\title{
Nepalese Kidney Transplant Recipient in a Follow up Clinic: Related and Unrelated Living Donor
}

\author{
Dulal RK, ${ }^{1}$ Karki S ${ }^{2}$ \\ 'Disease Prevention and Health Awareness Programme, Health Care Foundation-Nepal, ${ }^{2}$ Nepal Army Hospital, Ma- \\ hankal, Tundikhel, Kathmndu, Nepal
}

\section{ABSTRACT}

A cohort retrospective study was conducted on all follow up kidney transplant recipients at Transplant Follow up Clinic from June 16, 2003 to July 15, 2008. The main objective of this study was to find out the demographic pattern of the kidney transplant recipients and type of donors.

Among 452 recipients, the transplantation were done in India (449), Germany (2) and in the USA (1) with male to female ratio of 3:1. Kidney donors were unrelated $315(69.69 \%)$, related $134(29.43 \%)$ and some did not disclose 4 (0.88\%). Most of the kidney transplantation (93.75\%) were done in 45 different hospitals in India and about three quarters $(71.7 \%)$ of them were operated in the private hospitals in various states of India; only $2(4.16 \%)$ in Germany and $1(2.08 \%)$ in USA.

Newar was the largest population 142 (31.4\%) and second largest group was Mangol 124 (27.4.4\%) that comprised of Gurung, Rai, Magar, Tamang etc. Brahmins were the third largest population $91(20.1 \%)$. In this study the youngest recipients was 14 years and the oldest was of 75 years. The mean age was 41 (SD 13.84). This study showed that 35 (7.7\%) died, $8(1.7 \%)$ reported rejection and underwent re-transplantation and 238 patient have lost follow up till early 2008.

Kidney transplantation should be promoted as it is cheaper compared to dialysis in the long run. This study found that unrelated kidney donors have outnumbered the related donors in Nepalese kidney transplant recipients which emphasize the importance of unambiguous documentation and also a provision of lawful action against the middle-men if found involved in an illegal kidney related activities in Nepal. Organ transplantation is an important integral part of human health and should be regularize and promote lawfully to protect humans from trafficking for kidney, possible kidnapping, killing and stealing.

Key words: kidney transplantation, private hospitals, unrelated donors, safety. 
Dulal et al. Nepalese Kidney Transplant Recipient in a Follow up Clinic: Related and Unrelated Living Donor

\section{INTRODUCTION}

Kidney related disease has been emerging as a major public health burden in recent years. The precise data on end stage renal disease (ESRD) is not available in Nepal. However, national daily news papers reported various data which have not been authenticated by any medical literature. ${ }^{1,2}$ Chronic kidney diseases (CKD) requiring renal replacement therapy (RRT), are rising sharply worldwide, and the costs for the treatments even in developed nations are becoming staggering. Estimated global maintenance dialysis population is over 1.1 million and the size of this population has been expanding by $7 \%$ yearly. If the current rate continues the global ESRD population will exceed 2 million patients by 2010. An estimated incidence of ESRD in India and Pakistan is 100 per million but a recent study has reported 232/million ESRD cases in India. Based on the global scenario ESRD case in Nepal is estimated to be approximately $2600 /$ year. ${ }^{3,4}$

Principally, kidney diseases are categorized into two groups: (1) Acute kidney failure (ARF) that is known also as an acute renal injury (ARI) and the commonest causes in Nepal are gastroenteritis, sepsis, post surgical, trauma and obstretical complications, multiple hornet stings and acute urate nephropathy and different types of cross-injuries. ${ }^{5}$ Being buried under the rubble after earth quake or hit by a car or beaten by opponent can cause cross injuries that could lead to ARI. (2) Chronic kidney disease (CKD) that can eventually lead to endstage-renal disease (ESRD). ESRD is the severe (5th grade) stage of chronic renal failure with kidney damage for $\geq 3$ months manifested by pathological abnormalities (urine, blood) or imaging. ${ }^{6}$ The commonest causes of chronic kidney failure are uncontrolled diabetes, uncontrolled hypertension, chronic kidney illness, longterm obstruction on the urinary track due to stone or cyst and congenital diseases (polycystic kidney diseases) that applies to Nepalese context too. ESRD is with complete or near complete failure having $<15$ kidneys to function to excrete wastes and regulates electrolytes.

Kidney transplantation is the treatment of choice for most patients with ESRD. ${ }^{7}$ It has been legalized in Nepal since 2058/10/22 B.S. (2000 AD). ${ }^{8}$ Kidney transplantation performed in 3 patients in one of the nursing homes in Kathmandu in the year 1996 and one another transplantation done at central governmental hospital in November 2004 created just history. ${ }^{1,2}$ Finally, a couple of transplantation has been done successfully in August 2008. Potential related kidney donor's can be the father, mother, sister, brother, husband, wife, son, daughter, uncle, aunt, sworn friend
(Mitajyu), mother-in-law and father-in-law as set by land of law. Although the kidney from an unrelated donor is against the law, such transplantation is being reported in neighbouring countries including India..$^{9}$

The aim of this study was to find out the demographic pattern of kidney transplant recipient, type of kidney donors and type of hospital for transplantation; and create awareness and make alert policy makers.

\section{MATERIAL AND METHODS}

A cohort retrospective study was conducted on all follow up kidney transplant recipients at National Kidney Center (NKC) from June 16, 2003 to July 15, 2008. After intuitional approval, data were collected from a registered copy of kidney transplantation follow up recipients. Ethnicity was verified by direct telephone contact with kidney recipients to avoid misinterpretation of casts e.g. "Thapa". Thapa could be either a Thapa Magar that belongs to Mangol or Thapa Chhetri that belongs to Chhrtri. A prominent Sociologist was consulted regarding the minority casts to categorize them into respective ethnicity. Data were entered in to the Microsoft Excel 2003 and analyzed by Statistical Package for the Social Sciences, version 12.0 for windows.

\section{RESULTS}

A total of 452 follow up cases of transplant recipients visited at out patient clinic (OPD), NKC during five years period with male to female ratio of $3: 1$. Kidney donors were unrelated 315 (69.69\%), related 134 (29.43\%) and undisclosed 4 (0.88\%) (Figure 1$)$.

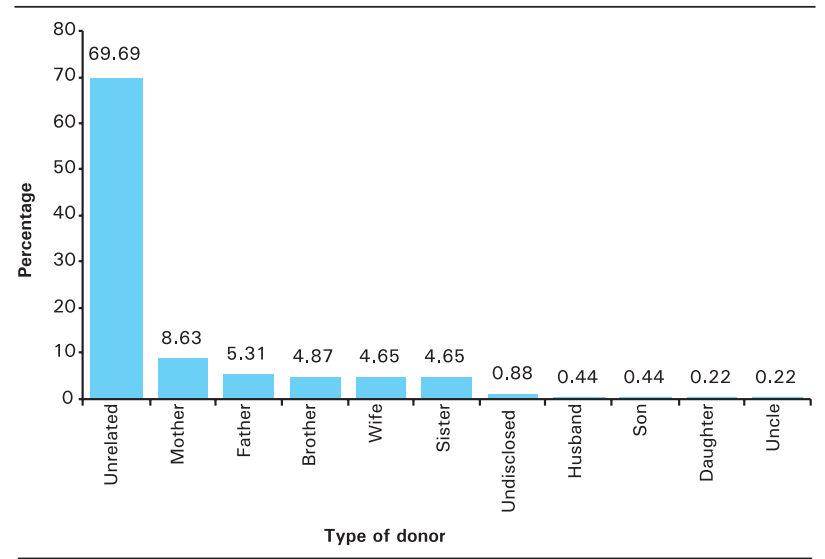

Figure 1. Type of kidney donor

Kidney recipients were from various ethnic groups, highest being Newar 142 (31.4\%) and second largest group was Mangol $124(27.4 .4 \%)$ that comprised of Gurung, Rai, Magar, Tamang etc. Brahmins 91 $(20.1 \%)$ were the third largest population (Table 1 ). 
Dulal et al. Nepalese Kidney Transplant Recipient in a Follow up Clinic: Related and Unrelated Living Donor

Table 1. Ethnicity of the recipients

\begin{tabular}{ll}
\hline Ethnicity & No \\
\hline Newar & $142(31.4 \%)$ \\
Mangol & $124(27.4 \%)$ \\
Brahmins & $91(20.1 \%)$ \\
Chhetri & $73(16.2 \%)$ \\
Dalit & $3(0.7 \%)$ \\
Others & $19(4.2 \%)$ \\
\hline
\end{tabular}

In this study the youngest one was 14 years and the two oldest were of 75 years old. The mean age was 41 (SD 13.84). The largest group of transplant recipients were from the age group $31-45$ years $(34.5 \%)$, second $46-60$ years $(31.9 \%)$ and the third largest group was $46-60$ years $(25 \%)$ (Table 2$)$.

Table 2. The age group of recipients

\begin{tabular}{ll}
\hline Age ( Years ) & No \\
\hline$\leq 15$ years & $4(0.9 \%)$ \\
$16-30$ & $113(25.0 \%)$ \\
$31-45$ & $156(34.5 \%)$ \\
$46-60$ & $144(31.9 \%)$ \\
$61-75$ & $35(7.7 \%)$ \\
\hline
\end{tabular}

Majority of kidney transplantation was done in India 449 (99.33\%), only 2 (0.44\%) were done in Germany and $1(0.22 \%)$ in the USA (Figure 2). Forty five different hospitals have been used for the transplantation purpose in India that includes private hospitals, missionary hospitals, trust hospitals, army hospital, government hospitals and even undisclosed (by transplant recipients). The transplant recipients who received kidney replacement in Germany did not disclose the name and nature of the hospital. Similary, four patients who got kidney transplantation in India also did not disclose the name of the hospitals in this study.

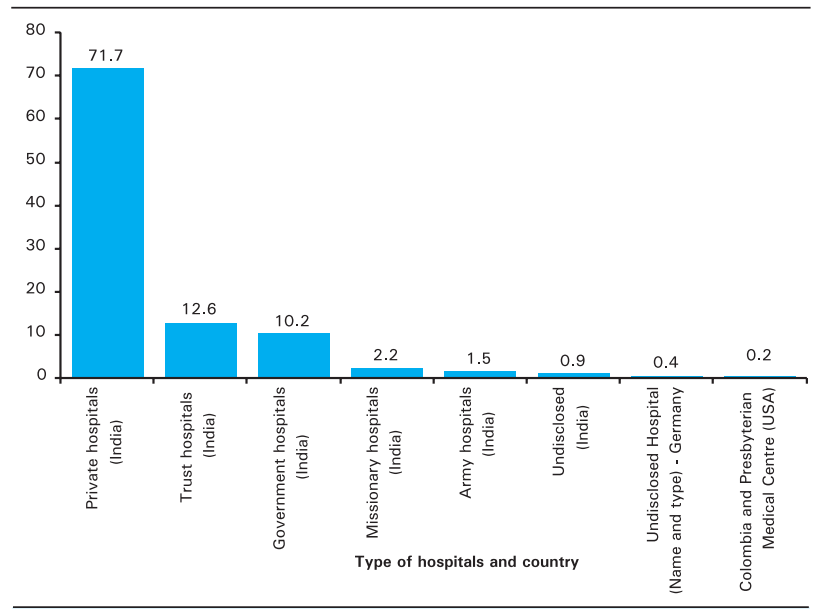

Figure 2. Transplantation done in various hospitals

The kidney recipient visiting the follow-up clinic was increasing steadily until 2006, but in the year 2007 and 2008 the number got decreased (Figure 3).

During five years of follow up after the transplantation our study showed that $35(7.7 \%)$ died, $8(1.7 \%)$ reported rejection and underwent re-transplantation and 238 patient have lost follow up till early 2008.

\section{DISCUSSION}

Chronic kidney diseases leading to ESRD has been increasing worldwide and Nepal is no exception to it. Kidney translation has been seen to as young as 14 years to as old as 75 years in our study. This variation in the age group shows that kidney disease has affected all walks of life. Mostly affected age group has been

Tranaplntation Year

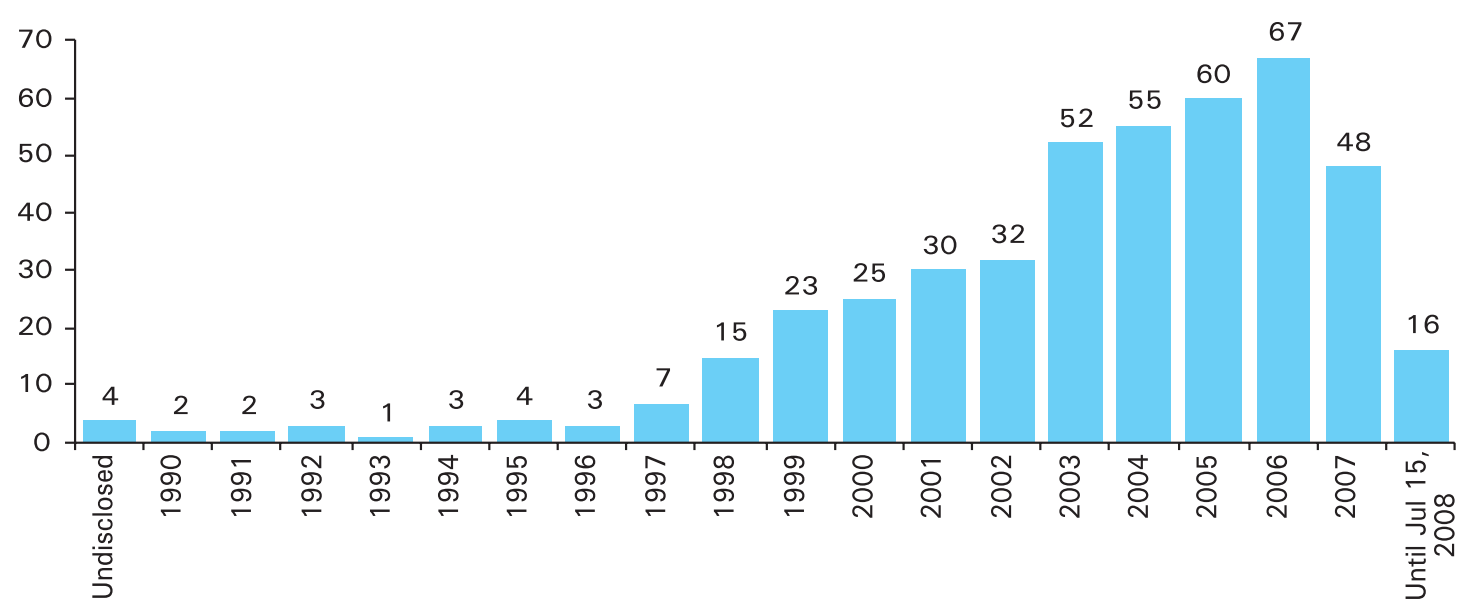

Figure 3. Kidney Transplant Recipient (1990 to 2008) 
31-45 years; about $8 \%$ were from 60 year and above. The patient comprises of male to female ratio $3: 1$. Out of 452 patients, about three quarters $(71.7 \%)$ of them were operated in the private hospitals in various states of India alone; and 449 transplantations performed were in 45 various hospitals that included private hospitals, missionary hospitals. Probably, the other settings including government one scrutinize the cases more seriously. Three quarters of transplant recipient received kidney from unrelated donors (70\%). Only two cases were operated in the Federal Republic of Germany for kidney replacement and one was operated in the United States of America for the same. In this study, most kidney transplant recipient age was between 2050 years, which is most productive age group causing more socioeconomic loss to family and the nation.

Potential kidney donor's can be the father, mother, sister, brother, husband, wife, son, daughter, uncle, aunt, sworn friend (Mitajyu), mother-in-law and fatherin-law as set by land of law. But, the percentage of unrelated $(69.69 \%)$ has outnumbered related donor $(29.43 \%)$ which indicates the significant illegal activity in kidney transplantation. It shows that there is an increasing trend for illegal activity in Nepalese people and even foreigner have claimed to have bought kidney in Nepal. ${ }^{10,11}$

The study finds only $4.65 \%$ wives donated kidney to their husband, but, only $0.44 \%$ husband donated kidney to their wives. The data indicates that kidney failure is more common in male than female. ${ }^{12}$ Mothers were slightly more than fathers $(8.63 \%$ vs. $5.31 \%)$ donating kidney. About $5 \%$ brothers and sisters donated kidney, but it was unclear whether it was elder or younger. Like in the West, it seems that some recipients were conscious about the data protection who did not want to disclose the source $(0.88 \%)$. It shows that at least few are concern about the privacy.

Majority of transplant recipient were Newar followed by Mangol and Bahum being the third (Table 1). The reason for increasing numbers in certain ethnicity couldn't be ruled out as it involves various factors like, economy, prevalence of disease, knowledge and information which needs further study on this aspect in Nepal. The truth is that the study centre is in Kathmandu where there are a majority of Newars residing. Hence, this observation can not be generalised for the entire country.

The ESRD are ever increasing and there is less likely to decrease it in future though this study shows decreasing trend of patients in the clinic (Figure 6). It is possible that the kidney recipients visited the Nephrologists in their private clinic as number of private clinics has been increasing for the last two years and could also be due to mortality.
Kidneys transplantation would be cheaper in the long run as compared to dialysis and provide an active life. Generally speaking, a kidney transplant is considered to be more cost-effective and more desirable for patients' quality of life than dialysis as shown by several studies. ${ }^{7,13}$

Paid kidney transplant are still being performed in several parts of India though this has been officially banned. ${ }^{14}$ In order to prevent illegal activities, Nepal could adapt modalities and establish its own donor-recipient system by developing lawful donor and recipient modality. It could also adapt Iranian model that establishes a compensated and regulated living-unrelated donor renal transplant program in 1988. According to this model - the transplant physician emphasizes the advantages of living-related donor compared with living-unrelated donor renal transplant and recommends renal transplantation from a living-related donor. If the patient has no living-related donor or the potential donor would not be willing to donate a kidney, then the patient is referred to Dialysis and Transplant Patients Association (DATPA) to locate a suitable living-unrelated donor. Those who volunteer as living-unrelated donors also contact DATPA. All members of DATPA are patients who have ESRD and receive no incentives for finding a living-unrelated donor or for referring the patient and donor to a renal transplant team. Dialysis units, transplant centers and DATPA offices all over Iran are active. There is no role for a broker or an agency in this program. All renal transplant teams belong to university hospitals, and the government pays all of the hospital expenses of renal transplantation. After renal transplantation, the living-unrelated donor receives an award and health insurance from the government. A majority of living-unrelated donors also receive a rewarding gift (arranged and defined by DATPA before transplantation) from the recipient or, if the recipient is poor, from one of the charitable organizations. The government also provides essential immunosuppressive drugs to all transplant recipients at a greatly subsidized and reduced price. Charitable organizations also are very active in providing these drugs or in paying any expenses of renal transplantation to poor patients. Renal transplant teams receive no incentives from the recipient or from the government's award. ${ }^{15}$

A Professor of Medicine and Bioethics claims that controlling the trade of kidney may a temporary remedy. Thus, a living non-related donor should be considered only when no living related or cadaver donor is available for the ESRD patient. ${ }^{16}$

The rapporteur for a committee of the European Parliament charged: “Organized trafficking in organs exists in the same way as trafficking in drugs. It involved killing people to remove organs which can be sold at a 
Dulal et al. Nepalese Kidney Transplant Recipient in a Follow up Clinic: Related and Unrelated Living Donor

profit. ${ }^{17} \mathrm{GTZ}$, Germany excavated shocking information and reported how organ traders are organized to make money where the author reported that street children in Latin America and children from impoverished families in Eastern Europe being kidnapped or sold and subsequently murdered for their organs. ${ }^{18}$

The researchers can not decline to accept similar drive in Nepal in the near future as anti-social activities that may be quite lucrative for middle-men. In the absence of a regulated good system, trafficking of human kidneys, stealing kidneys, kidnap and killing might be problem in Nepal in future. Although it is different fashion, some indications of anti-social activities have already surfaced e.g. Nepali poor and illiterate farmers' and carpet-weavers' kidney was removed but not paid payments as promised. It will be unwise to ignore the frontline news published by Nepali national news media. Otherwise, rich buyers will usually buy kidney through agents who hunt poor donors in need of money. As in the most market, if the demand far outweighs the supply, then the prices are driven up in the under ground market like with other commodities, although the organ trade is illegal. The authorities are being able to trace it sporadically only. At this point, it reminds the reports of a poverty-stricken village namely Hokse of Kavre district which is on the outskirt of Kathmandu became the epicentre of the organ trade in Nepal. ${ }^{19}$

The main limitation of our study was that the study center is not the place where transplantation is done despite of being largest center for providing dialysis and transplant follow up in Nepal. Therefore, we can not authenticate donor information given by the recipients. Usually transplantation is done elsewhere and due to various constraints they wish to monitor their kidney at local level. A well planned national level prospective study on related and unrelated donor in case of kidney transplant patient is must. Expansion of the success achieved by TUTH in kidney transplantation should be expanded in other reasons of the country and also other forms of RRT since all patients might not be fit for transplantation. ${ }^{20}$

\section{CONCLUSION}

Nepal has successfully conducted kidney transplantation in August 2008 and has entered into the new phase of kidney transplantation after legalization in 2002 $(2058 / 10 / 22$ BS). Privacy of the patients is respected in this study and data about individual is not disclosed. In general, this study has found that unrelated transplantations have outnumbered the related donor in Nepalese kidney transplant recipients. It emphasize the importance of unambiguous documentation and also a provision of lawful action against the middle-men if found involved in an illegal kidney related activities in Nepal. Organ transplantation is an important integral part of human health and should be regularize lawfully to protect humans from trafficking for kidney, possible kidnapping, killing and stealing kidneys. Health education and donor promotion is another aspect that needs more attention in our part.

A well regulated system like in Iran which could be responsible towards society and patients has become crucial in Nepal. As there is high demands and very low supply of kidney globally, unrelated kidney transplant is less likely to decrease. The adaption of models of paid kidney donation similar to the Iranian model or blood bank type model could save many lives.

\section{ACKNOWLEDGEMENT}

Thanks to the Executive Board Members of Health Care Foundation - Nepal for granting permission to conduct this study, Mr. Toy Nath Dawadi, Mr. Ram Nath Mandal, Mrs. Sangita Lamichhane and Mr. Bimal Baral for their help and support. Sincerest thanks to Mr. Dinesh Dulal who genuinely supported manuscript typing thoroughly.

\section{REFERENCES}

1. Tumbahangphey A. The worst disease for a Nepali [Online]. 2002 [cited 2008 Jul 1]; [2 screens]. Available from: URL: http://www.nepalnews.com.np/ntimes/issue97/nation_ 1.htm

2. Amgai T. Kidney Diseases Growing Risk [Online]. March 17, 2006. [cited 2008 Jul 1]; [1 screens]. Available from: URL: http://www.nepalnews.com

3. Perico N, Cordeanu I, Schieppati A, Remuzzi G. The Scientific care for prevention: An Overview. Kidney International, Prevention of Progression of Renal Disease. Kidney Int 2005; 67:S-8

4. Modi GK, Jha V. The incidence of End Stage Renal Disease in
India: A Population Based Study. Kidney Int 2006;70:2131-3.

5. Khakurel S, Satyal PR and Agrawal RK et al. Acute Renal Failure in a Tertiary Care Center in Nepal. J Nepal Med Assoc 2005 Apr-Jun;44 (158):32-5.

6. Snively CS. and Gutierrez CD. Chronic Kidney Disease: Prevention and Treatment of Common Complications, American Family Physician Vol. 70/No. 10 (November 15, 2004).

7. Shrestha BM and Haylor JL. Factors Influencing Long-term Outcomes following Renal Transplantation: A Review. J Nepal Med Assoc 2007;46(167):136 
Dulal et al. Nepalese Kidney Transplant Recipient in a Follow up Clinic: Related and Unrelated Living Donor

8. Kidney Transplantat Act 2058 (B.S.) in Compilation of Health Act and Regulations, Makalu Publication, Dillibazer, Kathmandu, Nepal, 5th Ed., Reprint in Fagun 2064:277-293. \{mirgaula pratyaropan (niyemit tatha nisedh) niyemawoli 2058), swastha sambandhi aain, niyemharuko sankalan, Makalu prakashan griha, Dillibazar, Kathmandu, Nepal, pachau saskaran, puna mudran 2064 Fahun:277-293.

9. Jha V and Chugh KS. The case against a regulated system of living kidney sales. Nature Clinical Practice Nephrology. 2006 Sept.; 2 (No 9):466-467.

10. Barsoum RS. Trends in unrelated-donor kidney transplantation in the developing world. Pediatr Nephrol. (Editorial commentary).

11. Gilioli A. I have bought a kidney in Nepal [Online]. May 172007 [cited 2008 Jul 1]; [8 screens]. Available from: URL: http:/ / espresso.repubblica.it/dettaglio//1613092

12. Ghaleb T. Renal failure in Yemen: a serious problem seeks attention [Online]. 2008 Mar 11 [cited 2008 Jul 1]; [3 screens]. Available from: URL:http://www.yobserver.com/sportshealth-and-lifestyle/10013887.html

13. Kaminota M. Cost-effectiveness analysis of dialysis and kidney transplants in Japan. Keio J Med 2001; 50 (2):100-108.

14. Jha V. Paid transplant in India: the grim reality. Nephrol Dial Transplant 2004;19(3):541-543.

15. Ghods AJ and Savaj S, Iranian Model of Paid and Regulated Living-Unrelated Kidney Donation. Clin J Am Soc Nephrol

\section{1: 1136-1145, 2006}

16. Alora AT. ORGANS (KIDNEYS) FOR A FEE OR FOR FREE [Accessed 18 March. 2008] Available from: URL:http:// webservice.mnl.ust.edu.ph/bioethics/papers/dec6/Organs $\% 20$ (Kidneys) $\% 20$ for $\% 20$ a $\% 20$ Fee $\% 20$ or $\% 20$ For $\% 20$ Free $\% 20$ by \%20Dr.\%20Angeles\%20Tan-Alora.pdf

17. Rothman DJ, Rose E and Awaya T et al. The Bellagio Task Force report on transplantation, bodily integrity, and the International Traffic in Organs. Transplant Proc 1997 Sep;29(6):2739-45.

18. Pearson E. Coercion in the Kidney Trade? A background study on trafficking in human organs worldwide Sector Project against Trafficking in Women. Deutsche Gesellschaft für Technische Zusammenarbeit (GTZ) GmbH. Postfach 5180 65726 Eschborn Germany Eschborn, April 2004. [Accessed 18 March. 2008] Available from: URL:http://www.gtz.de/de/ dokumente/en-svbf-organ-trafficking-e.pdf

19. Haviland C. Nepal's trade of doom [Online]. 2004 Sep 21 [cited 2008 Jul 1]; [3 screens]. [Accessed 18 March 2008]. Available from: URL:http://news.bbc.co.uk/2/hi/south_ asia/3674328.stm

20. Kidney transplant in Nepal possible, far cheaper too [Online] 2008 Aug. [Accessed 18 March. 2008] Available from: http:// www.kantipuronline.com/kolnews.php?\&nid=156967 